\title{
Grouping of Pseudomonas spp. Isolated from Dieback- Affected Sissoo (Dalbergia sissoo Roxb.) Using Phylogenetic Analyses
}

\author{
H.P. Mühlbach*, H. Tantau, A. Stubbe, D. Palm, J. Schulze, M.I. \\ Hoque $^{1}$, R.H. Sarker ${ }^{1}$, Sk. S. Alam ${ }^{1}$, M.L. Saha ${ }^{1}$ and Md. S. Khan ${ }^{2}$ \\ Biocentre Klein Flottbek, University of Hamburg, Hamburg, Germany
}

Key words: Grouping, Pseudomonus, Dieback-affected, Dalbergia sissoo, Phytogenetic analyses

\begin{abstract}
Dieback of sissoo (Dalbergia sissoo Roxb.) is a devastating plant disease, whose causative biotic agents were not yet identified unequivocally. Our previous studies revealed that bacteria belonging to the genus Pseudomonas were associated with dieback-affected sissoo trees. To study the bacterial community associated with dieback-affected sissoo trees, DNA based approaches were used in the present work. Sequencing almost the complete 16S rRNA gene of 33 selected Pseudomonas isolates allowed them to be grouped into two main clusters only. The major group consisted of 19 isolates related to P. oryzihabitans, while in the minor one ten isolates related to $P$. putida were found together with very few other pseudomonads. Almost the same clustering was obtained a with the independent grouping methods of amplified ribosomal DNA restriction analysis (ARDRA). These results strongly indicate that mainly bacteria strains related to Pseudomonas oryzihabitans were associated with dieback-affected Dalbergia sissoo trees. Immuno-histological studies with thin-sections of sissoo roots using Pseudomonas-specific antibodies showed that bacteria had invaded the root parenchyma.
\end{abstract}

\section{Introduction}

A novel form of sissoo (Dalbergia sissoo Roxb.) dieback has been recognized since 1993 as a dramatic threat for forests and timber production on the Indian subcontinent, including India, Nepal, Pakistan, Afghanistan and Bangladesh

*Author for correspondence: <muehlbach@botanik.uni-hamburg.de>. ${ }^{1}$ Department of Botany, University of Dhaka, Dhaka-1000, Bangladesh, ${ }^{2 B C S I R, ~ T i s s u e ~ C u l t u r e ~ S e c t i o n, ~ D h a k a-1205, ~}$ Bangladesh. 
(Shukla 2002). This dieback differs in certain characteristics from the previously described sissoo dieback, which was ascribed to infection by Fusarium solani sensu Snyder and Hansen (Bakshi 1954). In the new dieback disease, the susceptible sissoo trees are younger seedlings rather than older trees, and velocity of disease progression is increased (Baksha and Basak 2003). While abiotic (Webb and Hossain 2005) as well as biotic factors were discussed (Basak et al. 2003), the causal agent(s) for this new dieback had not yet been identified. A variety of fungal agents had been discussed as the cause of sissoo dieback (Manandhar and Shresta 2000, Dargan et al. 2002). However, fungi could not be identified consistently at all sites, so that their role as causative agents of dieback remained unclear (Baksha and Basak 2003).

In order to analyse putative microbial pathogens associated with samples from dieback-affected sissoo, we had initiated a series of joint studies that were conducted by our research groups at the Universities of Dhaka (Bangladesh) and Hamburg (Germany). The presence of plant pathogenic fungi was studied by sequencing the ribosomal internal transcribed spacer (ITS) DNA of fungal mycelia selected from dieback-affected and unaffected sissoo trees. A number of plant pathogenic as well as saprophytic fungi were detected, but the previously discussed Fusarium solani was not found (Tantau et al. 2011). These findings contradicted the hypothesis that one fungal species alone plays a role as causative agents of dieback, but rather supported the idea that fungi may be secondary parasites on dieback-affected sissoo trees (Tantau et al. 2011).

Since plant pathogenic bacteria have often been neglected as causative agents of severe plant diseases, bacteria isolated from samples of leaves, twigs, bark and roots of dieback-affected Dalbergia sissoo trees had been analysed previously (Tantau et al. 2005). By sequencing a 340 basepairs (bp) long stretch of the $16 \mathrm{~S}$ ribosomal RNA (rRNA) gene, bacteria of the genus Pseudomonas were identified in samples from heavily-infected sissoo trees (Tantau et al. 2005). Diseases of forest and fruit trees caused by Pseudomonas species are of major concern worldwide for forestry and cultivation of fruit trees (Kennelly et al. 2007). Therefore, further detailed studies on the taxonomy of Pseudomonas spp. and their role in the dieback of sissoo were conducted by Tantau et al. (2011). It was found that Pseudomonas was identified in $83 \%$ of 52 samples from diebackaffected trees, but only in two out of 15 samples (13\%) from apparently healthy trees (Tantau et al. 2011). However, allocation of individual isolates to Pseudomonas species through multilocus sequence typing using housekeeping genes such as $r n p B, r p o D, g a c A$, and $16 \mathrm{~S}$ rDNA were inconsistent (Tantau et al. 2011). In a more recent characterization of 28 Pseudomonas isolates, based on $16 \mathrm{~S}$ rDNA sequences and amplified fragment length polymorphism (AFLP) of 
genomic DNA, the isolates were found clustering in two clusters indicating at least two different species of Pseudomonas (Valdez et al. 2013). Biochemical characterization substantiated the genetically based taxonomy, as all Pseudomonas isolates were Gram-negative and catalase positive, but differed in oxidase activity (Valdez et al. 2013). In addition, hypersensitive response assays (HR) on indicator plants and infiltration experiments using seedlings of Dalbergia sissoo clearly indicated the plant pathogenic potential of Pseudomonas isolates (Tantau et al. 2011, Valdez et al. 2013).

The genus Pseudomonas is one of the most diverse taxonomic groups among plant pathogenic bacteria (Stead 1992). DNA-based approaches can reveal genetic diversity in much finer detail than classical taxonomic traits (Vinatzer and Bull 2009). Therefore, in the present investigation, we first included three more housekeeping genes for multilocus sequence typing. Finally, sequencing the almost complete $16 \mathrm{~S}$ rDNA and the technique of amplified ribosomal DNA restriction analysis (ARDRA, Vaneechoutte et al. 1993) were applied. These new results were compared with previously used tools in order to allow the identification of Pseudomonas isolates from sissoo trees on species level.

\section{Material and Methods}

Samples of leaves, second-order twigs, trunk bark and roots were collected from symptomless and from dieback-affected Dalbergia sissoo Roxb. at various sites in Bangladesh, as indicated in Tantau et al. (2011) and Valdez et al. (2013), including Dhaka, Tangail, Sirajganj, Bogra, along Jamuna Road, Rajshahi division, and Mirzapur, Dhaka division. Severity of dieback symptoms was rated as follows: 'unaffected': no typical symptoms of dieback visible; 'mild' (+): leaf chlorosis and necrosis and initial crown transparency; 'medium' (++): strong leaf necrosis, advanced crown transparency and gummosis (black spots) at the bottom of the trunk; 'severe' (+++): stagheadedness (loss of all small twigs) and many black spots on the whole trunk. Collected samples were kept cool in sealed plastic bags during transport and finally stored at $-70^{\circ} \mathrm{C}$.

Bacterial colonies were isolated as described in Valdez et al. (2013). Colony PCR and sequencing studies for extended multilocus sequence typing were done using the following primer pairs: 16S rDNA specific primers ' $\mathrm{Y} 1$ ' and ' $\mathrm{Y} 2$ ' (Young et al. 1991), which gave a PCR product of about $340 \mathrm{bp}$ in length; primers 'oprI' (De Vos et al. 1997) gave a partial sequence of $249 \mathrm{bp}$ of the gene oprI (outer membrane lipoprotein OprI), primers 'carA' (Hilario et al. 2004) yielded part (700 bp) of the gene carA (carbamoyl phosphate synthase small subunit), and primers 'recA' (Hilario et al. 2004) gave a $600 \mathrm{bp}$ sequence of the recA gene. Additionally, the taxon (Pseudomonas) selective primer pairs gacA-1F and gacA2 
(Costa et al. 2007) and rnpB-f (TAC GGA AAG TGC CAC AGA AAA) and rnpB-r (GGA GAG TCG ATC TRT AAG C) (Leif Kirsebom, pers. communication) were used.

Since confounding results were obtained with these approaches, PCR products representing the almost complete $16 \mathrm{~S}$ rRNA gene sequence were analysed. These sequences were obtained with primers 'U8-27' (AGA GTT TGA TCA TGG CTC AG) and 'R1494-1514' (CTA CGG TTA CCT TGT TAC GAC) (Kornelia Smalla, personal communication). To further characterize Pseudomonas isolates, amplified ribosomal DNA restriction analysis (ARDRA; Vaneechoutte et al. 1993) was used. Briefly, PCR amplicons of rDNA were obtained with primer pair 'U8-27' and 'R1494-1514' and were digested with Hin6I and Bsh1236I (5 U each, Fermentas) according to Weinert et al. (2010). Restriction fragments were analyzed in $4 \%$ agarose gels.

The program ClustalW (http://www.genome.jp/tools/clustalw/) was used for phylogenetic analyses, where trees are generated by the 'Unweighted Pair Group Method with Arithmetic Mean' (UPGMA). Following reference strains were used: Pseudomonas syringae, strain 10604 (DSMZ, Braunschweig, Germany) and Pseudomonas savastanoi, isolate B203 (collection K. Smalla, JKI Braunschweig, Germany).

For transmission electron microscopy (TEM) of bacterial isolates, cells from overnight cultures were inspected with TEM Leo 906 E (Carl Zeiss, Oberkochen, Germany) after negative staining with uranyl acetate.

Immuno-histological studies for the microscopic localisation of bacteria were performed with paraffin-embedded thin sections of root tissue collected from Dalbergia sissoo, using as primary antibody Anti-Pseudomonas-putida-antibodies (AP142, gemacbio, France) and as secondary antibody Anti-rabbit-IgG-alkaline phosphatase-antibody (A3687, Sigma, Germany) with BCIP/NBT-Kit 002209 (Life Technologies, Darmstadt, Germany) as substrate for the colorimetric detection.

\section{Results and Discussion}

Isolated bacterial colonies, the majority of which were found in samples collected from dieback-affected sissoo trees (with only a few ones isolated from apparently healthy trees), had been selected by colony PCR using Pseudomonas-specific primer pairs for $16 \mathrm{~S}$ rDNA, the gacA gene (encoding a highly specific transcription regulator) and the $r m p B$ gene (the RNA component of ribonuclease $P)$. The typical habitus of sample trees is shown in Fig. 1, where an apparently healthy sissoo tree (A) stands close to a dieback-affected one (B). All isolates that

could be allocated to the Pseudomonas group by this approach were further 
analysed by multilocus sequence typing using housekeeping genes. The following six characteristic loci of the bacterial genome were chosen: A $249 \mathrm{bp}$ fragment of the $r n p B$ gene, a $601 \mathrm{bp}$ long fragment of the gacA gene, a $249 \mathrm{bp}$ long fragment of the oprI gene (coding for major outer membrane lipoprotein I), a 700 bp long fragment of the car $A$ gene (encoding the small subunit of the carbamoyl-

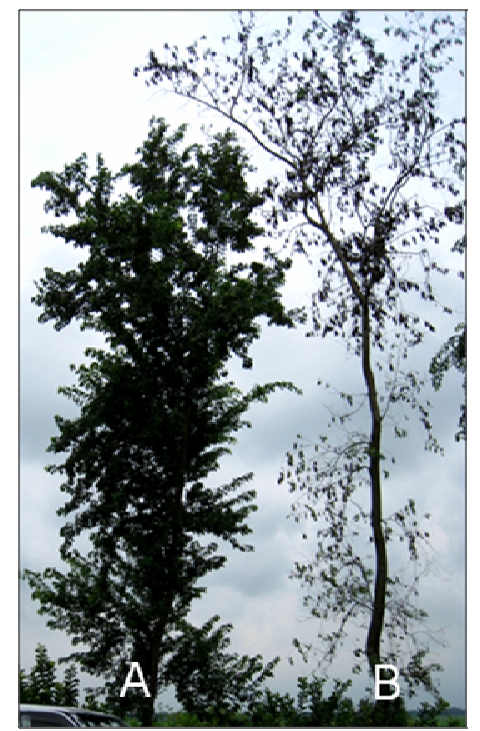

Fig. 1. Symptoms of dieback disease in Dalbergia sissoo. A. apparently healthy tree. B. Dieback-affected tree with medium symptoms (++).

phosphate synthetase), a $600 \mathrm{bp}$ long fragment of the $r e c A$ gene (encoding the recA protein, which is involved in pairing ssDNA and dsDNA during recombination) and the previously used $340 \mathrm{bp}$ long partial sequence of the $16 \mathrm{~S}$ ribosomal RNA gene (16S rDNA). While all sequences confirmed that the isolated bacteria are closely related to the Pseudomonas group, it turned out that, depending on the various gene sequences, the same isolate could be grouped with different species. In Fig. 2, this phenomenon is clearly evident for a few isolates that had been specifically selected because they exhibited properties of plant pathogenic bacteria in hypersensitive response assays and infiltration studies with Dalbergia sissoo seedlings (Tantau et al. 2011, Valdez et al. 2013). Isolate 113, for instance, was grouped in a cluster together with $P$. fluorescens, $P$. mendocina, P. aeruginosa, and $P$. stutzeri by the sequence of oprI (Fig. 2A), recA (Fig. 2C), and less pronounced by $r п p B$ (Fig. 2D), while it was found in a separate cluster together with $P$. putida by carA (Fig. 2B) and in more separated clusters by gacA (Fig. 2E) and by $16 \mathrm{~S}$ rRNA (Fig. 2F). Even more surprising was the varying positioning of isolates 113 and 1008, which had previously shown identical sequences in the 16S rRNA gene: by the sequence of recA each was found in a 
completely different cluster (Fig. 2C), while with $16 \mathrm{~S}$ rRNA, rnpB and gacA both isolates clustered together, as expected.
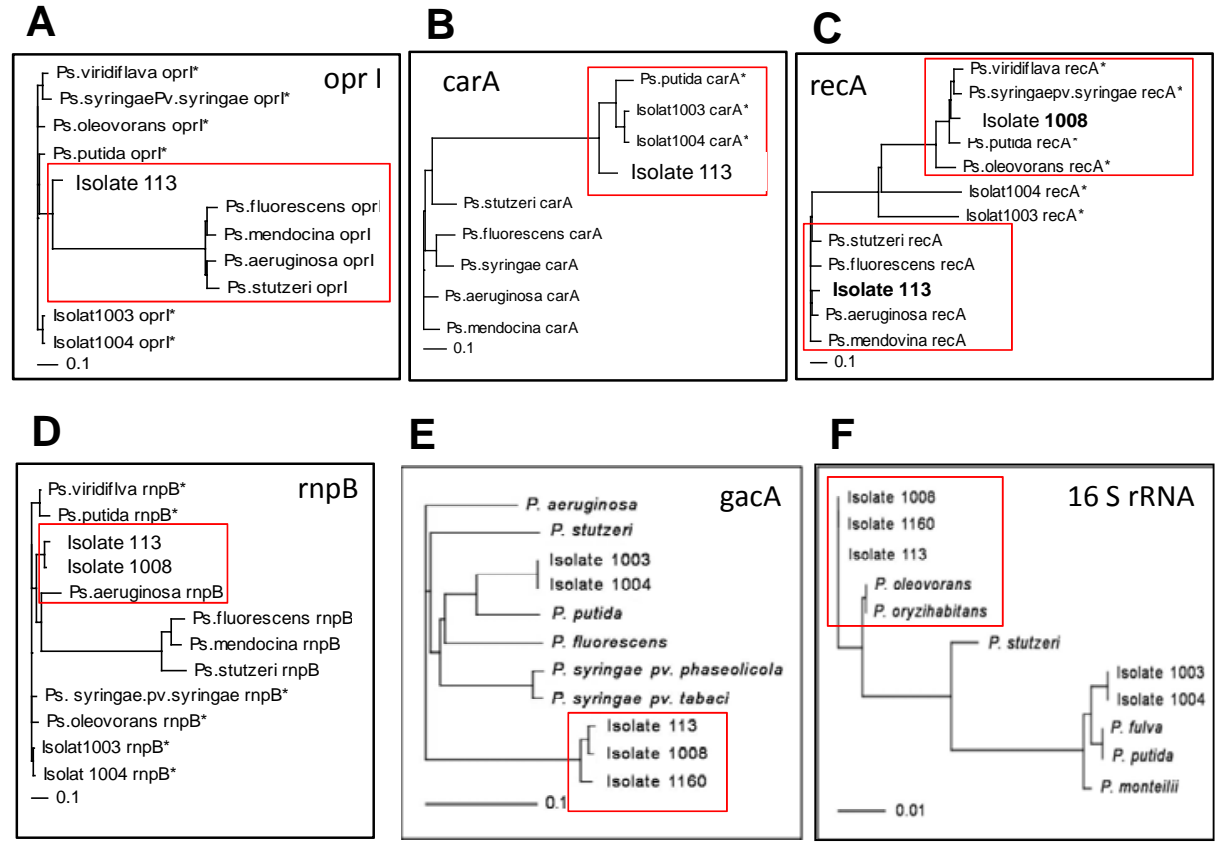

\section{E}

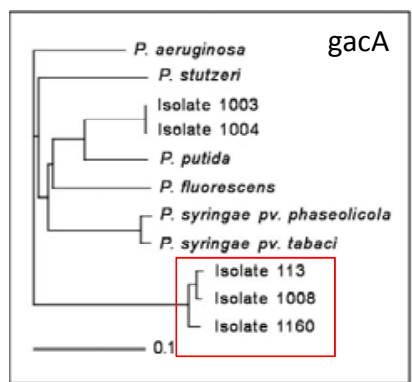

$\mathbf{F}$

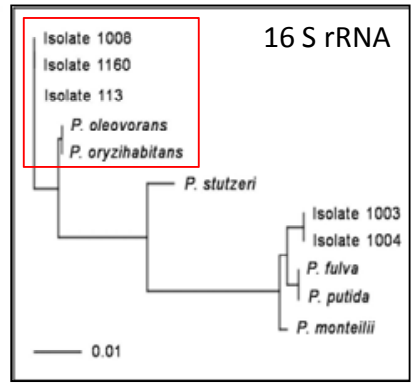

Fig. 2. Phylogenetic trees calculated using the program ClustalW based on partial sequences of following genes: A. oprI; B. carA; C. recA; D. rnpB; E. gacA; F. $16 \mathrm{~S}$ rRNA. A, B and C: this study; D, E, and F adopted from Mühlbach et al. (2011).

These confounding results prompted us to use the complete 16S rRNA coding sequence of 1506 bp (obtained with the primer pair 'U8-27' and 'R14941514 ') for the identification of a much wider selection of 33 Pseudomonas isolates. By these sequences 18 isolates were closely related to $P$. oryzihabitans and 10 isolates were related to P. putida, all with $99 \%$ identity. Among the remaining five, four isolates were found related to other pseudomonads and in one case to a more distantly-related species, Acinetobacter radioresistens. The phylogenetic analysis by ClustalW is shown in Fig. 3. Most of the isolates grouped in two main clusters, the major one (framed in red) harbouring the 18 isolates related to $P$. oryzihabitans and isolate 5-60-11, by sequence assigned as $P$. aeruginosa (with $97 \%$ identity to the next neighbouring isolate 1032, P. oryzihabitans). The minor cluster (framed in blue) was more heterogeneous: It represented the 10 isolates related to $P$. putida, which built a subcluster (framed with scattered blue lines), the two reference species used in this study ( $P$. syringae and $P$. savastanoi), forming 
another subcluster, and three less related species ( $P$. fulva, P. straminea, P. luteola). Isolate 10-1-9 (Acinetobacter radioresistens) was outside (Fig. 3).

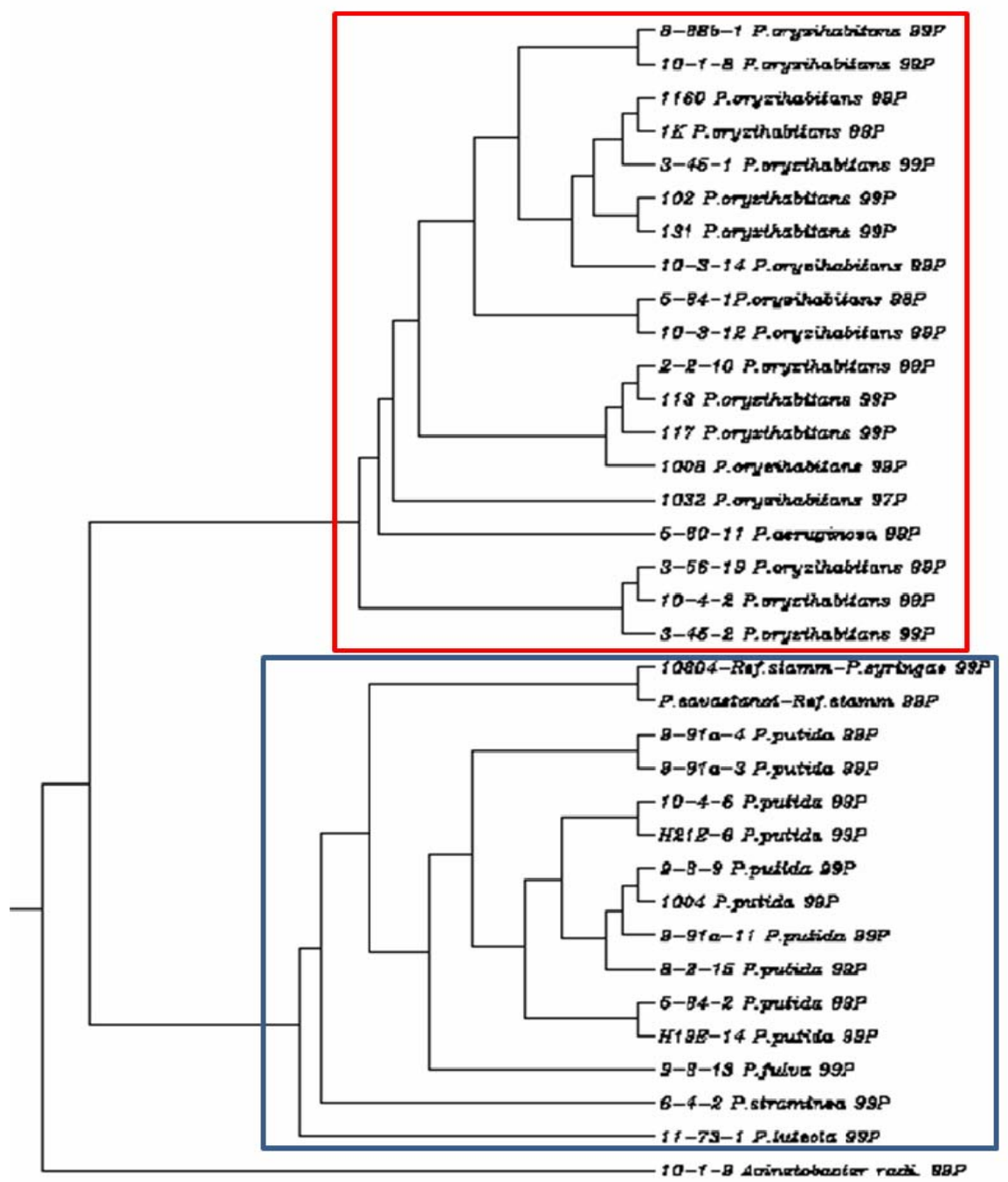

Fig. 3. Phylogenetic tree of Pseudomonas-related isolates based on a $1506 \mathrm{bp}$ long sequence encoding the $16 \mathrm{~S}$ rRNA. Trees calculated by neighbour joining.

These results were supported by the independent ARDRA technique, which grouped the isolates in a highly similar way by the restriction fragments pattern obtained from the PCR amplicon of $16 \mathrm{~S}$ rDNA. Representative results of gel electrophoresis are shown for 12 isolates in Fig. 4. A compilation of all results is given in Table 1. Again, all 18 isolates related to P. oryzihabitans represented the pattern indicated by the red frame in Fig. 4, together with isolate 11-73-1, which 
was by sequence related to $P$. luteola (Fig. 3). The second large group (yellow frame) was formed of nine isolates related to P. putida, and one related to $P$. fulva.

Table 1. Grouping of bacterial isolates by amplified ribosomal DNA restriction analysis (ARDRA) of PCR amplicons of the 16S rRNA gene.

\begin{tabular}{|c|c|c|c|c|c|c|c|c|c|c|c|}
\hline \multirow[t]{2}{*}{ Isolates } & \multicolumn{11}{|c|}{ Fragment size $^{1}[\mathrm{bp}]$} \\
\hline & $\begin{array}{c}1.000 / \\
956\end{array}$ & 700 & $\begin{array}{c}633 / \\
617\end{array}$ & $\begin{array}{c}386 / \\
405\end{array}$ & 875 & 654 & 517 & $\begin{array}{c}732 / \\
700\end{array}$ & $\begin{array}{l}553 / 59 \\
2 / 567\end{array}$ & 677 & 592 \\
\hline $10-4-2$ & + & + & + & + & ) & & & & & & \\
\hline $10-3-12$ & + & + & + & + & & & & & & & \\
\hline $10-3-14$ & + & + & + & + & & & & & & & \\
\hline $3-45-2$ & + & + & + & + & & & & & & & \\
\hline $3-56-19$ & + & + & + & + & & & & & & & \\
\hline $5-84-2$ & + & + & + & + & & & & & & & \\
\hline $11-73-1$ & + & + & + & + & & & & & & & \\
\hline $8-88 b-1$ & + & + & + & + & & & & & & & \\
\hline $3-45-1$ & + & + & + & + & & & & & & & \\
\hline $5-84-1$ & + & + & + & + & & \multirow{2}{*}{\multicolumn{3}{|c|}{ P. oryzihabitans }} & & & \\
\hline $2-2-10$ & + & + & + & + & & & & & & & \\
\hline 1008 & + & + & + & + & & & & & & & \\
\hline 1160 & + & + & + & + & & & & & & & \\
\hline 1032 & + & + & + & + & & & & & & & \\
\hline 117 & + & + & + & + & & & & & & & \\
\hline 131 & + & + & + & + & & & & & & & \\
\hline 102 & + & + & + & + & & & & & & & \\
\hline $1 \mathrm{~K}$ & + & + & + & + & & & & & & & \\
\hline 113 & + & + & + & + & & & & & & & \\
\hline $10-1-8$ & + & + & + & + & & & & & & & \\
\hline $10-1-9$ & & & & & + & + & + & \multicolumn{4}{|c|}{ Acinetobacter radiores } \\
\hline $9-91 a-3$ & & & & & & & & + & & & \\
\hline $9-91 a-4$ & & & & & & & & + & + & & \\
\hline $9-3-13$ & & & & & & & & + & + & & \\
\hline $8-2-15$ & & & & & & & & + & + & & \\
\hline $10-4-6$ & & \multirow{2}{*}{\multicolumn{2}{|c|}{ P. putida }} & & & & & + & + & & \\
\hline $9-3-9$ & & & & & & & & + & + & & \\
\hline 9-91a-11 & & & & & & & & + & + & & \\
\hline H19E-14 & & & & & & & & + & + & & \\
\hline H21E-6 & & & & & & & & + & + & & \\
\hline 1004 & & & & & & & & + & + & & \\
\hline P. syringae & & & & & & & & + & + & & \\
\hline P. savastanoi & & & & & & & & + & + & & \\
\hline$\hat{0}-4-2$ & \multirow{2}{*}{\multicolumn{3}{|c|}{$\begin{array}{l}\text { P. straminea } \\
P . \text { aeruginosa }\end{array}$}} & & & & & & & + & + \\
\hline $5-60-11$ & & & & & & & & & & + & + \\
\hline
\end{tabular}

${ }^{1}$ Fragment sizes were estimated from separation in $4 \%$ agarose gels. 
That group also included the reference strains $P$. syringae and $P$. savastanoi. Isolates 6-4-2 (P. straminea) and 5-60-11 (P. stutzeri) formed an independent group (green frame), as did isolate 10-1-9 (Acinetobacter rdioresistens, blue frame).

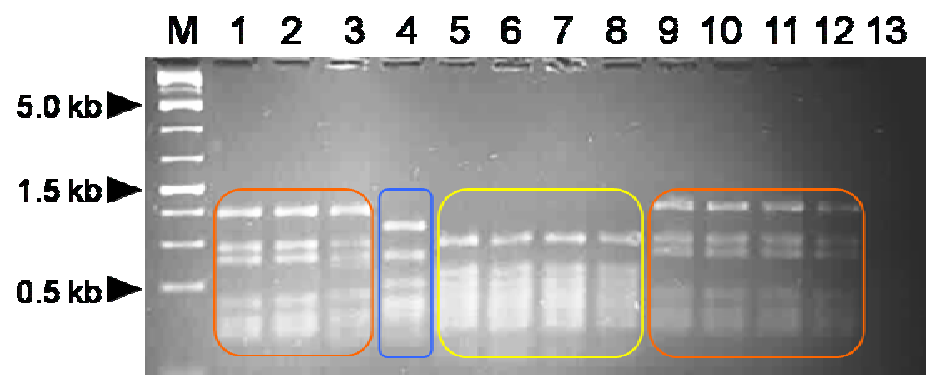

Fig. 4. Amplified ribosomal DNA restriction analysis (ARDRA) of 12 bacteria strains isolated from dieback-affected and unaffected Dalbergia sissoo trees. Lane-M. Gene Ruler $1 \mathrm{~kb}$ Plus DNA ladder; Lane-1. Isolate 10-4-2 (P. oryzihabitans); Lane-2. Isolate 10-3-12 (P. oryzihabitans); Lane-3. Isolate 10-3-14 (P. oryzihabitans); Lane-4. Isolate 10-1-9 (Acinetobacter radioresistens); Lane-5. Isolate 9-91a-3 (P. putida); Lane-6. Isolate 9-91a-4 ( . putida); Lane-7. Isolate 9-3-13 ( $P$. fulva); Lane-8. Isolate 8-2-15 (P. putida); Lane-9. Isolate 3-45-2 (P. oryzihabitans); Lane-10. Isolate 3-56-19 (P. oryzihabitans); Lane-11. Isolate 5-84-2 (P. oryzihabitans); Lane-12. Isolate 11-73-1 (P. luteola); Lane-13. Water control.

From the 19 isolates that formed the 'oryzihabitans' group using both approaches, 14 were found in dieback-affected sissoo trees $(73.7 \%)$, while 5 were associated with trees that did not exhibit typical dieback symptoms. In contrast, the more heterogeneous 'putida' group showed a different association: only 6 out of 13 isolates were detected in dieback affected trees.

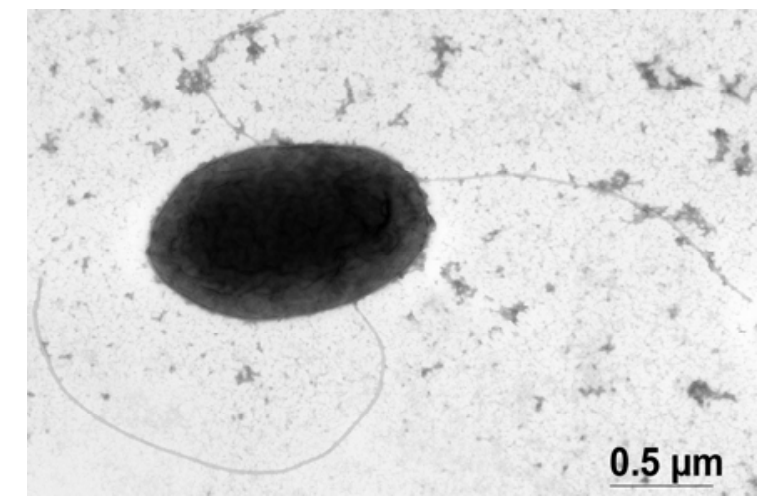

Fig. 5. Transmission electron microscopy of isolate 1008, related by $16 \mathrm{~S}$ rDNA sequence to Pseudomonas oryzihabitans (99\% identity).

TEM studies with several isolates revealed ellipsoid, flagellate cells of 1.5 to 2 $\mu \mathrm{m}$ length. As an example, isolate 1008, related to P. oryzihabitans, is shown in Fig. 5. 
To investigate the presence and spatial distribution of bacteria in root tissue of dieback-affected sissoo trees, thin-sections of root samples collected in Bangladesh were analysed by serological detection of Pseudomonas using antiPseudomonas-antibodies and colorimetric staining (Fig. 6). The presence of bacteria was indicated by blue blotches, scattered in the parenchyma tissue (Fig. 6A). Some cells appeared destroyed. As negative controls, either samples from unaffected trees were treated in the same way (Fig. 6C) or samples were stained unless applying the anti-Pseudomonas antibodies (Fig. 6 B, D). In all these cases, no blue staining was observed.

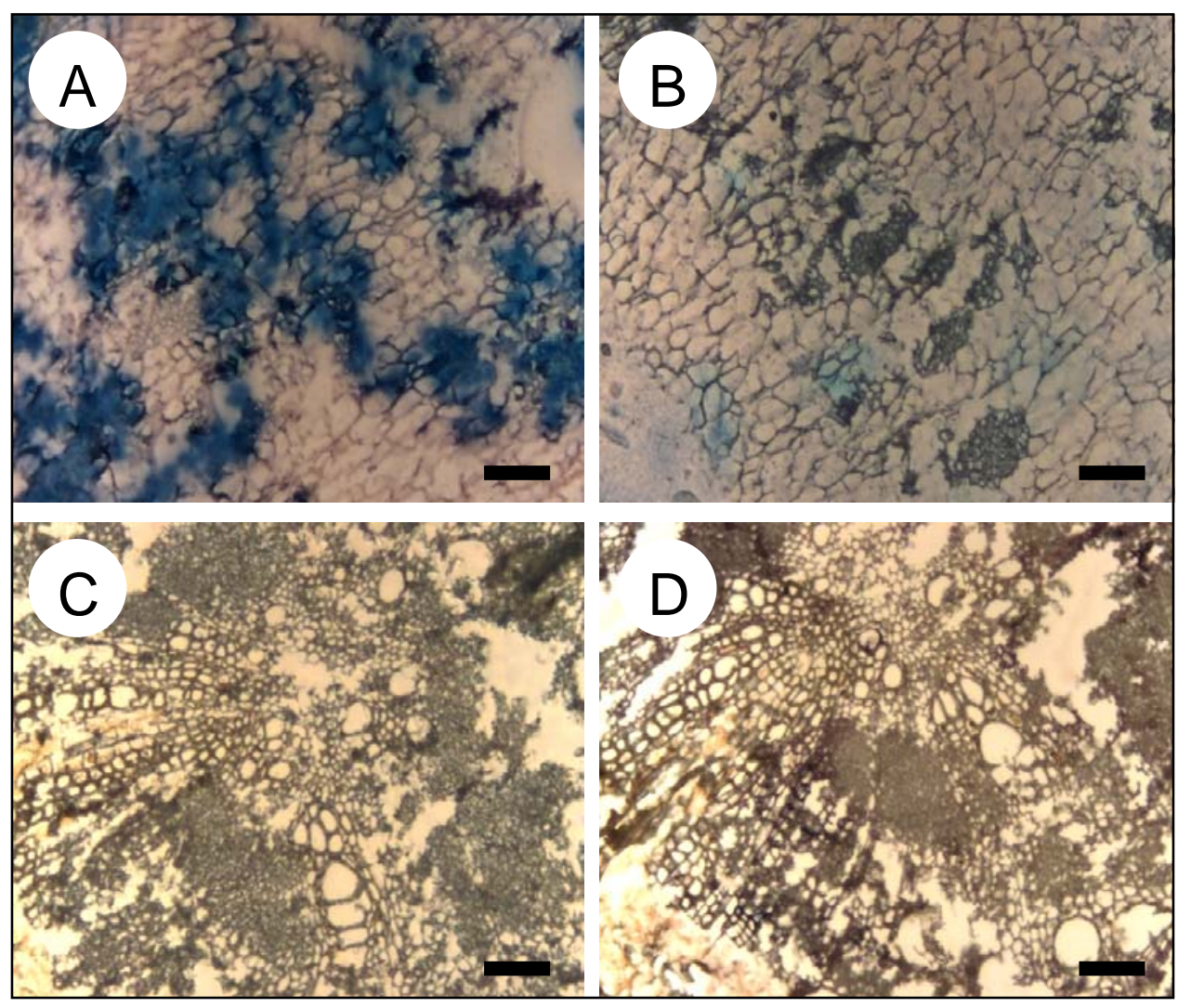

Fig. 6. Immuno-histological detection of Pseudomonas thin sections of roots from dieback-affected Dalbergia sissoo. A. Dieback-affected tree sample stained with anti-Pseudomonas-antibodies and anti-rabbit-IgG-antibody-alkaline-phosphatase-conjugate ('second antibody'), bar represents 100 $\mu \mathrm{m}$; B. Same tree sample as in A, stained only with second antibody, bar represents $100 \mu \mathrm{m}$; C. Unaffected tree sample stained with anti-Pseudomonas-antibodies and anti-rabbit-IgG-antibodyalkaline-phosphatase-conjugate ('second antibody'), bar represents $250 \mu \mathrm{m}$; D. Same tree sample as in C, stained only with second antibody, bar represents $250 \mu \mathrm{m}$. 
In conclusion, these new data confirmed our previous observations of the association of Pseudomonas with the dieback disease of Dalbergia sissoo. Most of the presently characterized isolates group into two clusters, representing two species of Pseudomonas, namely P. oryzihabitans and P. putida. The association of two different Pseudomonas species was already concluded from an earlier study using AFLP analyses (Valdez et al. 2013). With the present study, we show that strains related to $P$. oryzihabitans were mainly isolated from dieback-affected trees. Pseudomonas oryzihabitans was first isolated in 1985 from rice paddies and clinical specimens (Kodama et al. 1985). Its ecological function is still unclear, but in recent investigations, it was found antagonistic to nematodes and fungi as well as pathogenic to tomato roots (Vagelas and Gowen 2012). Therefore, the strains of P. oryzihabitans found in Bangladesh in association with Dalbergia sissoo still deserve much deeper characterization.

\section{Acknowledgements}

The authors thank Dr. Kornelia Smalla, JKI Braunschweig, for her help in establishing the ARDRA technique. The indispensable excellent technical assistance of Heidrun Meyer is gratefully acknowledged. They also thank Karen Dehn, Martina Brumm-Scholz and Elke Woelken, whose support in the studies using light and electron microscopy has been of great value. This work was generously supported by Mrs. Ilse Tantau and the Mathias-Tantau-Stiftung.

\section{References}

Baksha MW and Basak AC (2003) Mortality of sissoo (Dalbergia sissoo Roxb.) and its management in Bangladesh. In: Baksha MW (ed.): Mortality of Sissoo (Dalbergia sissoo) and top dying of Sundri (Heritiera fomes) in Bangladesh, pp. 1-6. Bangladesh Forest Research Institute, Chittagong.

Bakshi BK (1954) Wilt of shisham (Dalbergia sissoo Roxb.) due to Fusarium solani sensu Snyder and Hansen. Nature 174: 278-279.

Basak AC, Baksha MW and Khair MA (2003) Symptom and extent of damage caused by wilting of sissoo (Dalbergia sissoo Roxb.) in Bangladesh. In: Baksha MW (ed.): Mortality of Sissoo (Dalbergia sissoo) and Top Dying of Sundri (Heritiera fomes) in Bangladesh, pp. 39-42. Bangladesh Forest Research Institute, Chittagong.

Costa R, Gomes NC, Krogerrecklenfort E, Opelt K, Berg G and Smalla K (2007) Pseudomonas community structure and antagonistic potential in the rhizosphere: insights gained by combining phylogenetic and functional gene-based analyses. Environ. Microbiol. 9: 2260-2273.

Dargan JS, Dhingra GS, Kuldeep L and Lalji K (2002) Pathological problems and mycoflora associated with Dalbergia sissoo plantations in Punjab. Plant Disease Research 17: 269-277. 
De Vos D, Lim A, Pirnay JP, Struelens M, Vandenvelde C, Duinslaeger L, Vanderkelen A, Cornelis P (1997) Direct detection and identification of Pseudomonas aeruginosa in clinical samples such as skin biopsy specimens expectorations by multiplex PCR based on two outer membrane lipoprotein genes, oprI and oprL. J. Clin. Microbiol. 35: 1295-1299.

Hilario E, Buckley TR, Young JM (2004) Improved resolution on the phylogenetic relationships among Pseudomonads by the combined analysis of atpD, carA, recA and $16 \mathrm{~S}$ rDNA. Antonie van Leeuwenhoek 86: 51-64.

Kennelly MM, Cazorla FM, de Vicente A, Ramos C and Sundin GW (2007) Pseudomonas syringae diseases of fruit trees - Progress toward understanding and control. Plant Dis. 91: 4-16.

Kodama K, Kimura N and Komagata K (1985) Two new species of Pseudomonas: P. oryzihabitans isolated from rice paddy and clinical specimens and P. luteola isolated from clinical specimens. Int. J. Syst. Bacteriol. 35: 467-474.

Manandhar G and Shresta SK (2000) Fungi associated with dieback of sissoo. In: Apanah S, Allard G, AmatyaSM (Eds.), Proceedings of the Sub-regional Seminar "Die-back of Sissoo (Dalbergia sissoo)" Kathmandu, Nepal 25-28 April 2000. Bangkok, FORSPA, Food and Agriculture Organisation of the United Nations: 27-29.

Mühlbach HP, Tantau H, Renk S, Schultz D, Woelki S, Meyer H, Schulze J, Palm D, Stubbe A, Fennemann M, Valdez N, Sarker RH, Alam Sk.S, Saha ML, Khan S and Hoque MI (2011) Molecular detection and characterisation of biotic agents associated with dieback disease of Dalbergia sissoo Roxb. in Bangladesh. In: Role of Biotechnology in Food Security and Climate Change. Islam AS, Haque MM, Sarker RH, Hoque MI (Eds.) Proc. Sixth Intl. Plant Tissue Cult. \& and Biotech. Conf., December 3-5, 2010, Bangladesh Assoc. Plant Tissue Cult. \& Biotech. Dhaka, Bangladesh. pp. 131-143.

Shukla AN (2002) Mortality of Dalbergia sissoo in India. Indian Forester 128: 1209-1215.

Stead DE (1992) Grouping of plant pathogenic and some other Pseudomonas spp. by using cellular fatty acid profiles. Int. J. Syst. Bacteriol. 42: 281-295.

Tantau H, Hoque MI, Sarker RH and Mühlbach HP (2005) 16S rDNA sequence analysis of bacterial isolates from dieback-affected sissoo trees (Dalbergia sissoo Roxb.) in Bangladesh. J. Phytopathol. 153: 517-521.

Tantau H, Renk, S, Schultz D, Meyer H, Schulze J, Palm D, Stubbe A, Valdez Aguirre N, Sarker RH, Alam SkS, Saha ML, Khan S, Hoque MI and Mühlbach HP (2011) Infectivity assays and sequence analyses for unassigned Pseudomonas species as putative cause of dieback disease of Dalbergia sissoo Roxb. in Bangladesh. Plant Tissue Cult. \& Biotech. 21 (2): 101-113.

Vagelas I and Gowen SR (2012) Control of Fusarium oxysporum and root-knot nematodes (Meloidogyne spp.) with Pseudomonas oryzihabitans. Pak. J. Phytopathol. 24: 32-38.

Valdez N, Karlovsky P, Dobrindt L, Hoque MI, Sarker RH, Tantau H and Mühlbach HP (2013) Role of bacteria in dieback disease of Dalbergia sissoo Roxb.. Bangladesh J. Bot. 42 (1): 1-16.

Vaneechoutte M, De Beenhouwer H, Claeys G, Verschraegen G, De Rouck A, Paepe N, Elaichouni A and Portaels F (1993) Identification of Mycobacterium species by using amplified ribosomal DNA restriction analysis. J. Clin. Microbiol. 31: 2061-2065. 
Vinatzer BA and Bull CT (2009) The impact of genomic approaches on our understanding of diversity and taxonomy of plant pathogenic bacteria. In: Plant Pathogenic Bacteria - Genomics and Molecular Biology. Jackson RW (Ed.), Caister Academic Press, Norfolk, UK. pp. 37-61.

Webb EL and Hossain SMY (2005) Dalbergia sissoo mortality in Bangladesh plantations: correlations with environmental and management parameters. Forest Ecology Management 206: 61-69.

Weinert N, Meincke R, Gottwald C, Heuer H, Schloter M, Berg G, Smalla K (2010) Bacterial diversity on the surface of potato tubers in soil and the influence of the plant genotype. FEMS Microbiol. Ecol. 74: 114-123.

Young JPW, Downer HL and Eardly BD (1991) Phylogeny of the phototrophic Rhizobium strain BTAil by polymerase chain reaction-based sequencing of a 16 rRNA gene segment. J. Bacteriol. 173: 2271-2277. 